\title{
Treatment of cystoid macular edema with the new-generation NSAID nepafenac $0.1 \%$
}

\author{
Seenu M Hariprasad' \\ Levent Akduman ${ }^{2}$ \\ Joseph A Clever ${ }^{2}$ \\ Michael Ober ${ }^{3,4}$ \\ Franco M Recchia ${ }^{5}$ \\ William F Mieler ${ }^{1,6}$ \\ 'Department of Ophthalmology \\ and Visual Sciences, Vitreoretinal \\ Service; ${ }^{6}$ Department of Ophthalmology \\ and Visual Sciences, University \\ of Chicago, Chicago, IL, USA; \\ ${ }^{2}$ Vitreoretinal Service, Saint Louis \\ University Eye Institute, Saint Louis, \\ MO, USA; ${ }^{3}$ Vitreoretinal Service, \\ Henry Ford Health Systems, West \\ Bloomfield, MI, USA; ${ }^{4}$ Retinal \\ Consultants of Michigan, Southfield, \\ MI, USA; ${ }^{5}$ Vitreoretinal Service, \\ Vanderbilt Eye Institute, Nashville, \\ TN, USA
}

Correspondence: Seenu M Hariprasad University of Chicago, Department of Ophthalmology and Visual Sciences, 584I S. Maryland Avenue - MC 21I4, Chicago, IL 60637, USA

Tel + I 773795 I326

Fax+I 7737028094

Email retina@uchicago.edu
Purpose: To describe the use of nepafenac $0.1 \%$ for cystoid macular edema (CME).

Methods: This was a multicenter retrospective review of $22 \mathrm{CME}$ cases (20 patients) treated with nepafenac $0.1 \%$ ( six with concomitant prednisolone acetate $1 \%$ ) from December 2005 to April 2008: three acute pseudophakic CME cases, 13 chronic/recalcitrant pseudophakic CME cases, and six cases of uveitic CME. Pre- and post-treatment retinal thickness and visual acuity were reported.

Results: Following treatment for six weeks to six months, six eyes with uveitic CME showed a mean retinal thickness improvement of $227 \pm 168.1 \mu \mathrm{m}$; mean best-corrected visual acuity (BCVA) improvement was $0.36 \pm 0.20 \log$ MAR. All three cases of acute pseudophakic CME improved after four to 10 weeks of nepafenac, with a mean improvement in retinal thickness of $134 \pm 111.0 \mu \mathrm{m}$. BCVA improved in two patients ( 0.16 and $0.22 \log$ MAR) but not in the third due to underlying retinal pigment epithelium changes. Thirteen eyes with chronic/recalcitrant pseudophakic CME demonstrated a mean improvement in retinal thickness of $178 \pm 128.7 \mu \mathrm{m}$ after nepafenac and mean BCVA improvement of $0.33 \pm 0.19 \log$ MAR.

Conclusion: The positive outcomes of these 22 eyes strongly suggest that nepafenac $0.1 \%$ is a promising drug for the treatment of CME. Additional study under randomized controlled conditions is warranted.

Keywords: macular edema, NSAID, nepafenac, cataract surgery, uveitis

\section{Introduction}

Cystoid macular edema (CME) is a serious consequence of cataract surgery and other ocular procedures and conditions, resulting sometimes in transient or even permanent vision loss. The incidence of subclinical, angiographic CME is approximately $20 \%-30 \%$ of uncomplicated cataract surgery cases, ${ }^{1,2}$ while acute, clinically significant CME has been reported from $1 \%-2 \%$ of patients following uncomplicated phacoemulsification. ${ }^{3,4}$ Macular edema secondary to uveitis is also a common problem, occurring in up to $48 \%$ of uveitic eyes. ${ }^{5}$

Many studies have shown an association between CME and inflammation. ${ }^{6-9}$ For this reason, $\mathrm{CME}$ is commonly treated with anti-inflammatory agents. Corticosteroids can effectively prevent and treat $\mathrm{CME},{ }^{10,11}$ but are associated with serious side effects, including elevated intraocular pressure (IOP), posterior subcapsular cataract, and exacerbation of and increased susceptibility to concomitant infections. ${ }^{12-14}$ Thus, safer alternative treatments are desirable.

Topical nonsteroidal anti-inflammatory drugs (NSAIDs) have demonstrated efficacy in prophylaxis and/or treatment of CME. ${ }^{15-19}$ Because corticosteroids and NSAIDs inhibit prostaglandin synthesis by different mechanisms, an additive or synergistic effect is possible with combined therapy. Studies have confirmed the benefits of combination therapy ${ }^{10,20}$ and it is now widely accepted that a combination of NSAID + steroid be initiated upon documentation of clinical CME. ${ }^{21}$ Although none of the approved topical NSAIDs 
have an indication for the treatment or prevention of CME, this accounts for widespread off-label use of these drugs.

The newest topical NSAID to earn Food and Drug Administration (FDA) approval for the treatment of pain and inflammation associated with cataract surgery is nepafenac $0.1 \%\left(\right.$ Nevanac $\left.^{\circledR}\right)$. Nepafenac is the only topical NSAID with a prodrug structure; nepafenac is converted to its more active metabolite amfenac by intraocular hydrolases present in vascular ocular tissues, including the retina/choroid. ${ }^{22}$ Case series have already been reported suggesting that nepafenac $0.1 \%$ has activity against various etiologies of CME. ${ }^{23,24}$ The retrospective cases presented below add to the evidence that the off-label use of nepafenac $0.1 \%$ is effective as treatment for pseudophakic and uveitic CME.

\section{Methods}

A retrospective review was performed on 22 cases (20 patients) of documented CME from four academic centers treated between 2005 and 2008 with nepafenac 0.1\% $\left(\mathrm{Nevanac}^{\circledR}\right.$, Alcon Laboratories, Inc., Fort Worth, TX, USA) three times daily (TID). These cases were chosen for their representative response to nepafenac treatment. CME was documented by observing retinal edema on optical coherence tomography (OCT) using a Stratus OCT 3 (Carl Zeiss Meditec, Inc., Dublin, $\mathrm{CA}$ ) and a reduction in Snellen best-corrected visual acuity (BCVA). Acute pseudophakic CME was defined as untreated CME with a duration of less than six months, whereas chronic pseudophakic CME was classified as any CME persisting for at least six months. CME that had failed prior therapy was labeled recalcitrant. Nepafenac treatment was discontinued when substantial improvements in visual acuity and/or retinal thickness were documented. The specific cases presented below are representative examples of each type of CME.

\section{Results}

\section{Uveitic CME}

Five of the six uveitic eyes were recalcitrant to previous CME therapy, with four failing ketorolac + prednisolone acetate $1 \%$ and one failing prednisolone alone (Table 1). After six weeks to six months of treatment with nepafenac $0.1 \%$ TID (three eyes received concurrent prednisolone acetate 1\%), CME improved in all six eyes. Retinal thickness decreased by an average of $227 \pm 168.1 \mu \mathrm{m}$ and vision improved by an average of $0.36 \pm 0.20 \log$ MAR.

\section{Patient \# I}

A 42-year-old man presented with bilateral recalcitrant CME secondary to pars planitis. He had failed previous combination therapy with prednisolone acetate $1 \%$ and ketorolac $0.4 \%$ (Acular LS ${ }^{\circledR}$, Allergan, Inc., Irvine, CA, USA) for eight months. His BCVA at the time of presentation was $20 / 80$ in the right eye and 20/100 in the left eye. The left eye, which had a central retinal thickness of $667 \mu \mathrm{m}$, was treated with intravitreal triamcinolone. Four weeks later (after administration of triple IOP-lowering drops decreased IOP from $56 \mathrm{mmHg}$ to $22 \mathrm{mmHg}$ ), the retinal thickness in the left eye had decreased to $204 \mu \mathrm{m}$ and BCVA had improved to $20 / 25$. Instead of injecting the right eye with intravitreal triamcinolone, as the patient was now a known "steroid responder", the decision was made to treat three times daily (TID) with nepafenac $0.1 \%$ for three months. At the completion of therapy, right eye central retinal thickness had decreased from $695 \mu \mathrm{m}$ to $164 \mu \mathrm{m}$ and BCVA had improved to $20 / 20$ (Figure 1).

\section{Acute pseudophakic CME}

For the three cases of acute pseudophakic CME, improvement occurred after 4-10 weeks of treatment with nepafenac $0.1 \%$ with or without prednisolone acetate $1 \%$ (Table 2). One of the three patients did not achieve an improvement in vision, but this was due to underlying retinal pigment epithelium (RPE) changes from dry age-related macular degeneration rather than any residual edema.

\section{Patient \#6}

A 75-year-old woman was diagnosed with CME in the right eye one month after uncomplicated phacoemulsification and posterior chamber intraocular lens (IOL) implantation, showing a central retinal thickness of $448 \mu \mathrm{m}$ and visual acuity of $20 / 50$. She was started on treatment with nepafenac $0.1 \%$ TID and prednisolone acetate 1\% QID (four times daily); within one month of treatment the CME had completely resolved, with a retinal thickness of $211 \mu \mathrm{m}$ and BCVA of 20/40 (Figure 2). Upon completion of the remainder of her medication, her vision improved further to 20/30.

\section{Chronic/recalcitrant pseudophakic CME}

Pseudophakic CME cases that met the criteria for chronic and/ or recalcitrant $\mathrm{CME}$ were grouped together. Nine of the 13 eyes in this category had been treated unsuccessfully with combination old generation NSAID/prednisolone therapy for as long as 16 months (Table 3). Of the remaining four eyes, two were treated with prednisolone acetate $1 \%$ alone, one was treated with ketorolac $0.5 \%$ alone, and the other had received no prior treatment. After 1-8 months of treatment with nepafenac $0.1 \%$ (two eyes were treated concomitantly with prednisolone 


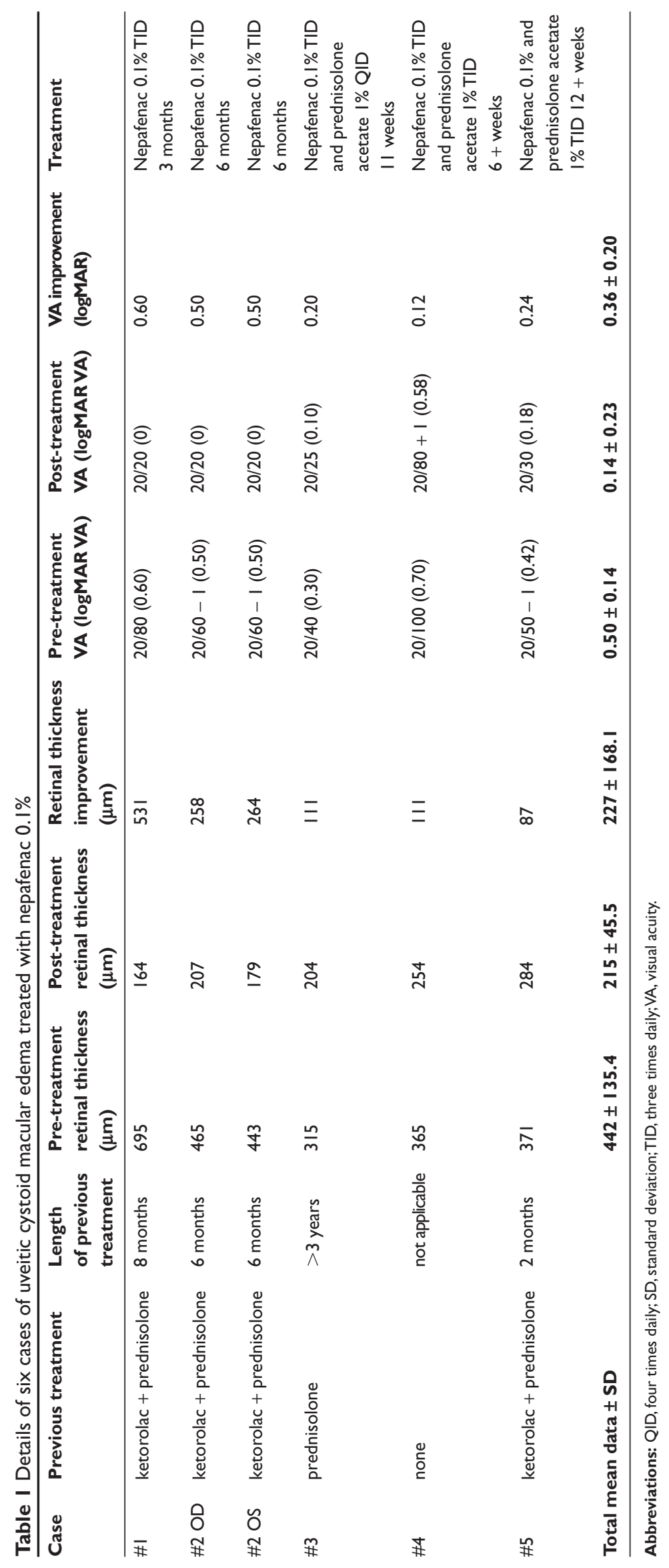




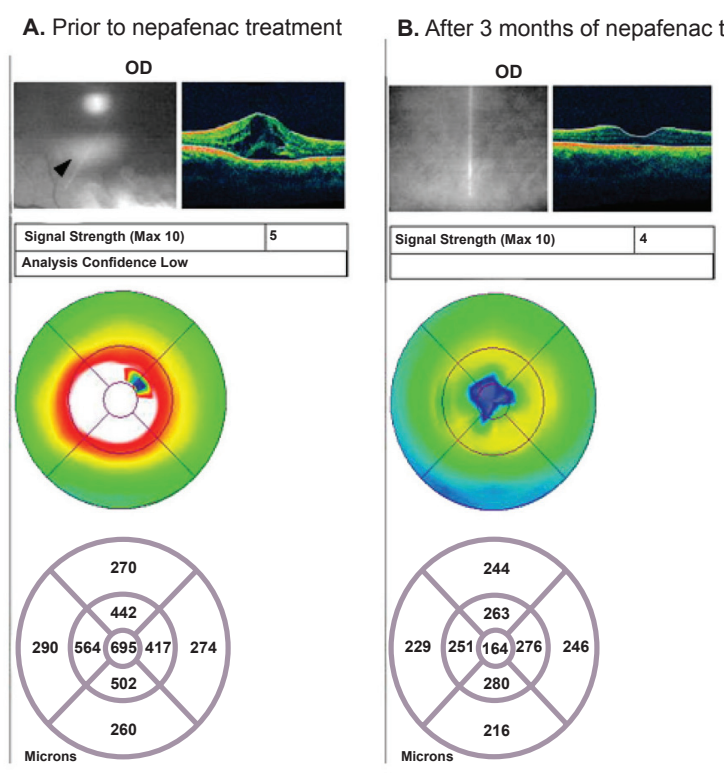

Figure I Recalcitrant uveitic CME: Patient \#I OCT images. A) The patient shows retinal edema and cystoid spaces (see arrow), with a retinal thickness of $695 \mu \mathrm{m}$ prior to nepafenac treatment. B) The patient shows resolution of retinal edema, with a retinal thickness of $164 \mu \mathrm{m}$ after three months of nepafenac treatment.

Abbreviations: CME, cystoid macular edema; OCT, optical coherence tomography.

acetate $1 \%$ ), improvement in retinal thickness was observed in all cases but one. At the most recent visit, these eyes showed a mean decrease in retinal thickness of $178 \pm 128.7 \mu \mathrm{m}$ and a mean improvement in visual acuity of $0.33 \pm 0.19 \log$ MAR. Five of the 13 eyes continue to receive nepafenac $0.1 \%$ in an attempt to produce complete resolution of CME.

\section{Patient \#12}

A 69-year-old woman was diagnosed with CME in the right eye after undergoing uncomplicated cataract surgery. She was initially treated with ketorolac $0.5 \%$ and prednisolone acetate $1 \%$ for six months, but failed to respond to therapy; OCT image after treatment showed a retinal thickness of $690 \mu \mathrm{m}$ and visual acuity was 20/60 (Figure 3). Ketorolac and prednisolone were discontinued and nepafenac was initiated. One month after TID administration of nepafenac $0.1 \%$ alone, retinal thickness had improved to $262 \mu \mathrm{m}$ and BCVA was $20 / 30$.

All highlighted patients were representative of the other patients within each category.

\section{Discussion}

Although no randomized, controlled clinical trials have yet been reported on the ability of nepafenac $0.1 \%$ to treat $\mathrm{CME}$, evidence is mounting that this drug has promising activity against macular edema of varying etiologies. One recently reported case series illustrates the positive impact

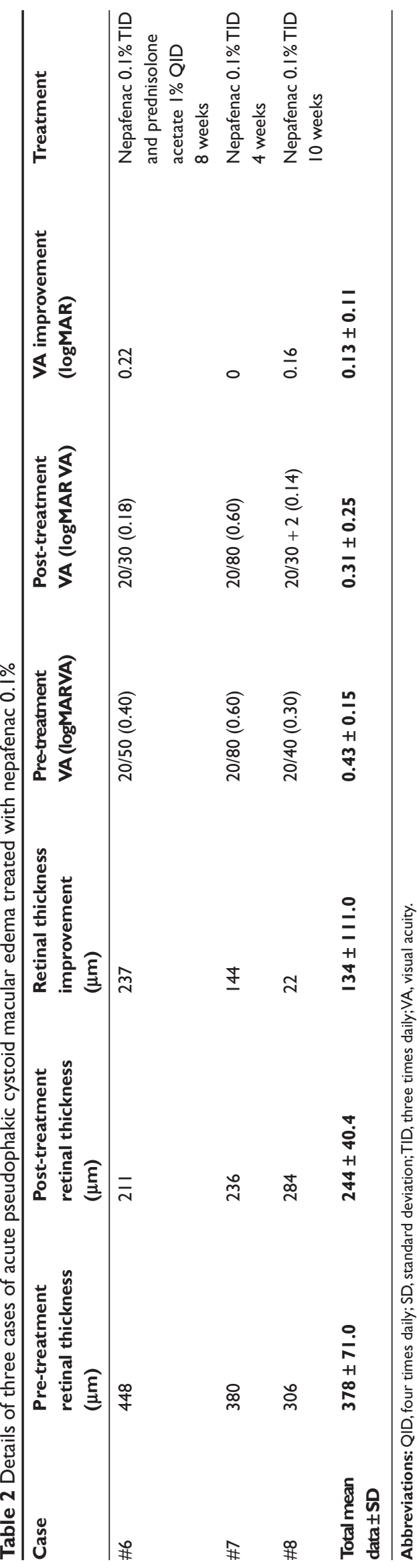




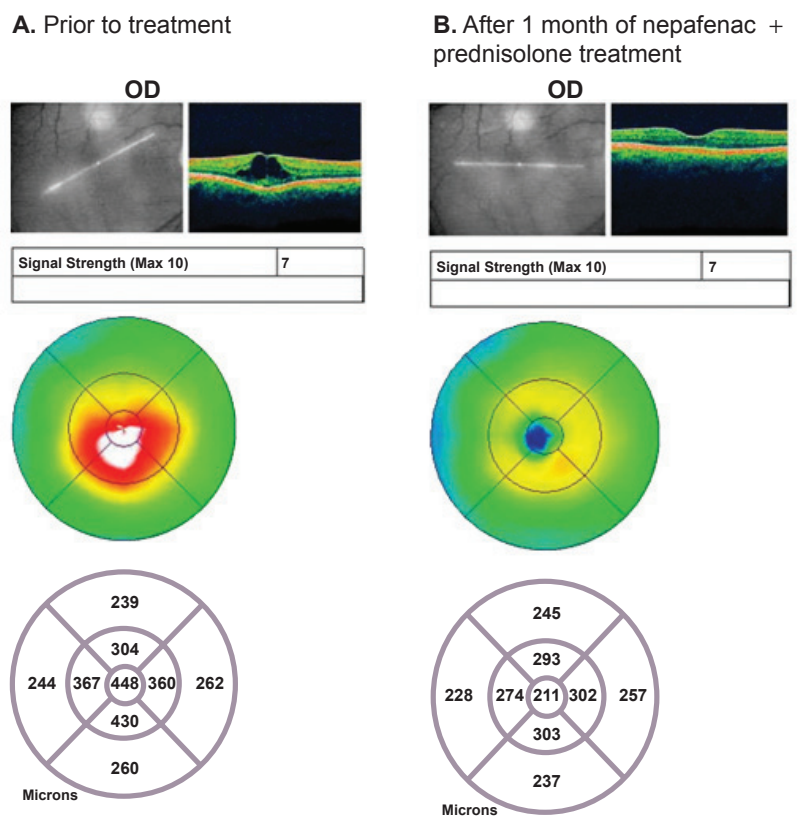

Figure 2 Acute pseudophakic CME: Patient \#6 OCT images. A) The patient shows retinal edema, with a retinal thickness of $448 \mu \mathrm{m}$ prior to treatment. B) The patient shows resolution of retinal edema, with a retinal thickness of $211 \mu \mathrm{m}$ after one month of treatment with nepafenac + prednisolone.

Abbreviations: CME, cystoid macular edema; OCT, optical coherence tomography.

of nepafenac on acute and chronic CME, even in patients who have failed combination treatment with a steroid and a conventional NSAID. ${ }^{23}$ Another report focuses on the successful use of nepafenac for the treatment of chronic uveitic CME. ${ }^{24}$ Other reports demonstrate the resolution of macular edema by nepafenae $0.1 \%$ in steroid responders, ${ }^{25}$ and in patients with diabetic macular edema. ${ }^{26}$ In addition to CME treatment, nepafenac $0.1 \%$ may also have prophylactic activity against CME, as suggested by Wolf and colleagues, who recently published a retrospective study of 450 consecutive patients with CME showing that those treated with prednisolone alone had a higher incidence of CME than those treated with prednisolone + nepafenac $0.1 \%{ }^{4}$

The positive outcomes of the patients presented in the current study, showing reduction in/resolution of macular edema and improvement in visual acuity, provide additional evidence that nepafenac can effectively treat multiple types of CME. Therefore, this report adds to the body of evidence supporting an important role for nepafenac $0.1 \%$ in the treatment of macular edema. Of note, over half the cases responded to nepafenac treatment following failure of the conventional NSAID ketorolac. Although macular edema improved quickly in all three cases of acute CME in the current study, it must be noted that acute CME typically resolves spontaneously, making it difficult to determine the role of nepafenac on this improvement.
The conversion of the prodrug nepafenac into its more active metabolite, amfenac, is performed by intraocular hydrolases; ${ }^{22}$ these enzymes are present in ocular tissues such as the cornea and iris/ciliary body, but are at their highest concentrations in the retina/choroid. ${ }^{27}$ This fact should provide an effective targeting of active drug to the macula, perhaps providing an advantage over conventional NSAIDs, none of which have a prodrug structure.

Preclinical studies do, in fact, support this hypothesis. Ex vivo studies using rabbit retina/choroid tissues demonstrated that nepafenac $0.1 \%$ reached its peak activity (suppression of prostaglandin production) sooner than diclofenac $0.1 \%$ (40 minutes vs 80 minutes). ${ }^{22}$ Moreover, nepafenac $0.1 \%$ produced greater and more sustained prostaglandin inhibition than diclofenac $0.1 \%{ }^{22} \mathrm{Ke}$ and colleagues showed that compared to diclofenac, nepafenac exhibited 6-fold faster corneal permeability, likely due to its neutral prodrug structure $;{ }^{27}$ logic would suggest that faster entry into the anterior chamber may translate to faster entry into the posterior chamber as well. Finally, results from an in vivo rabbit study of concanavalin A-induced retinal edema showed that nepafenac inhibited retinal inflammation, as measured by blood-retinal barrier breakdown and prostaglandin synthesis, significantly better than either diclofenac or ketorolac. ${ }^{28}$

Therefore, preclinical studies have demonstrated not only the targeted bioactivation of nepafenac, but also its increased absorption, greater activity and longer duration of action in the posterior segment relative to conventional NSAIDs; these characteristics suggest that nepafenac would perform favorably compared to conventional NSAIDs in the prevention and treatment of retinal edema. The relatively small number of cases presented here support, although they cannot prove, this hypothesis. However, they do warrant formal investigation of nepafenac in placebo- and active-controlled trials for the treatment of CME.

\section{Acknowledgments}

The authors would like to thank Jennifer Klem, $\mathrm{PhD}$, for medical writing assistance. Publication support provided by Alcon Laboratories Inc.

\section{Disclosure}

Drs. Hariprasad, Ober, Recchia are on the Alcon Speakers Bureau and have participated in Alcon Advisory Boards. This manuscript was previously presented at the American Society of Cataract and Refractive Surgeons, Chicago, IL, USA, April, 2008. This research was funded in part by the Research to Prevent Blindness Organization, New York, NY, USA. 


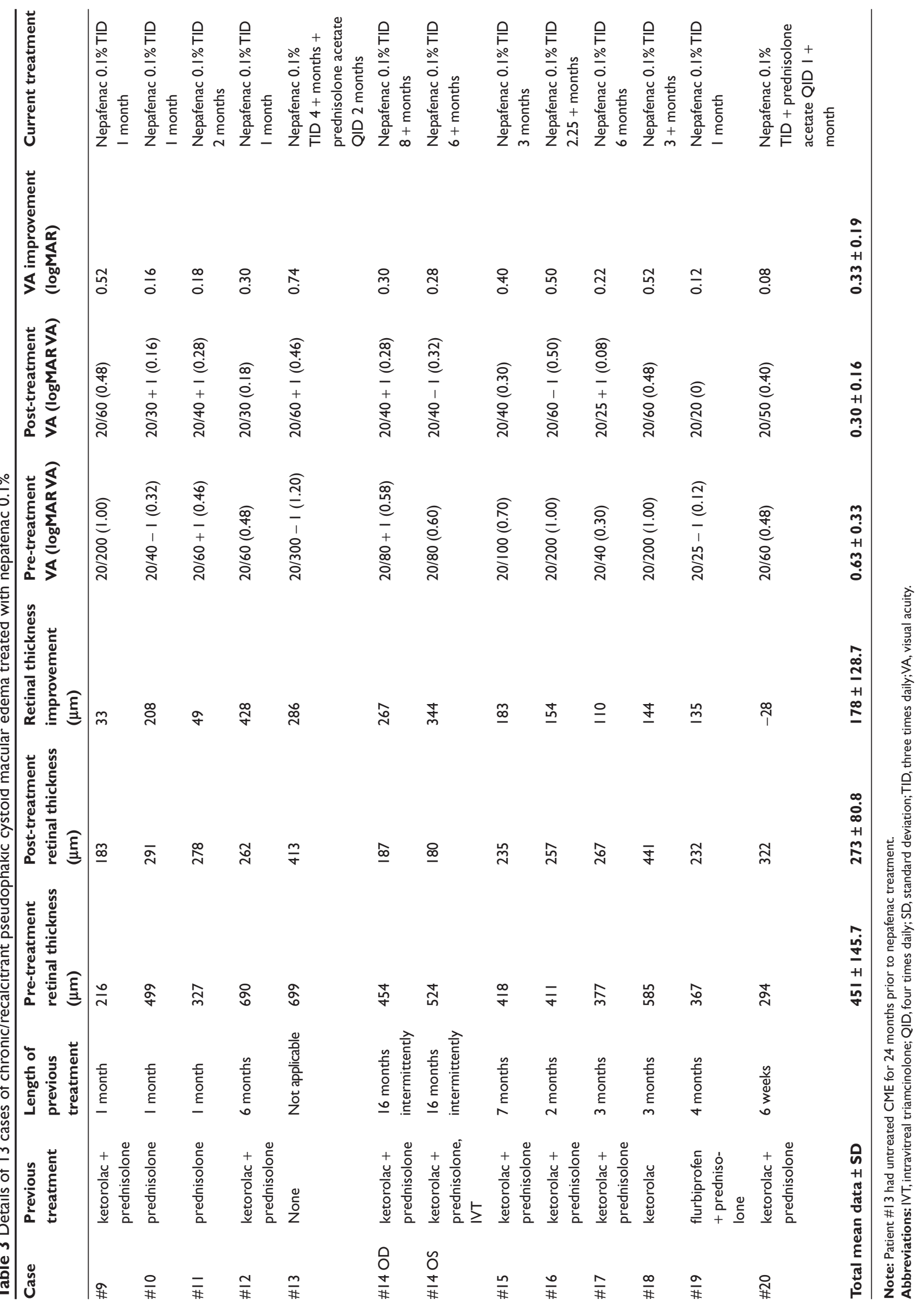




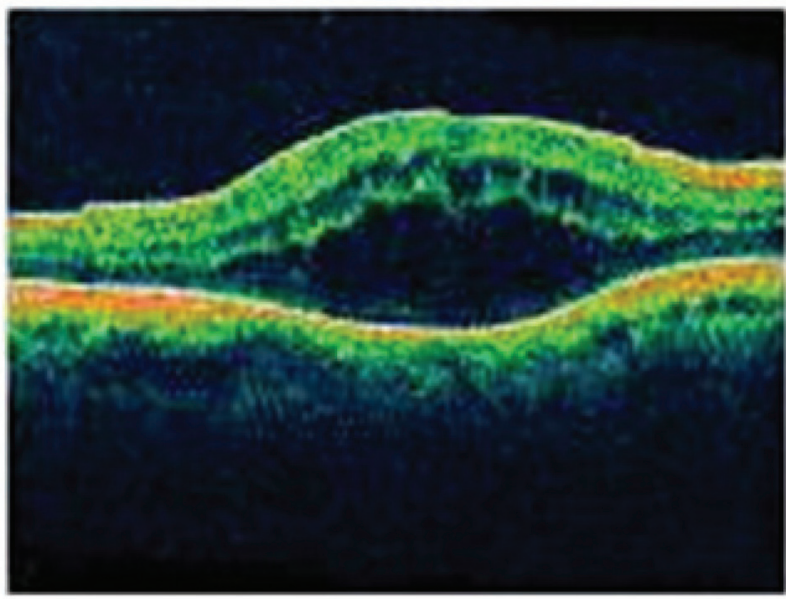

A. Prior to nepafenac treatment $(690$ microns $)$

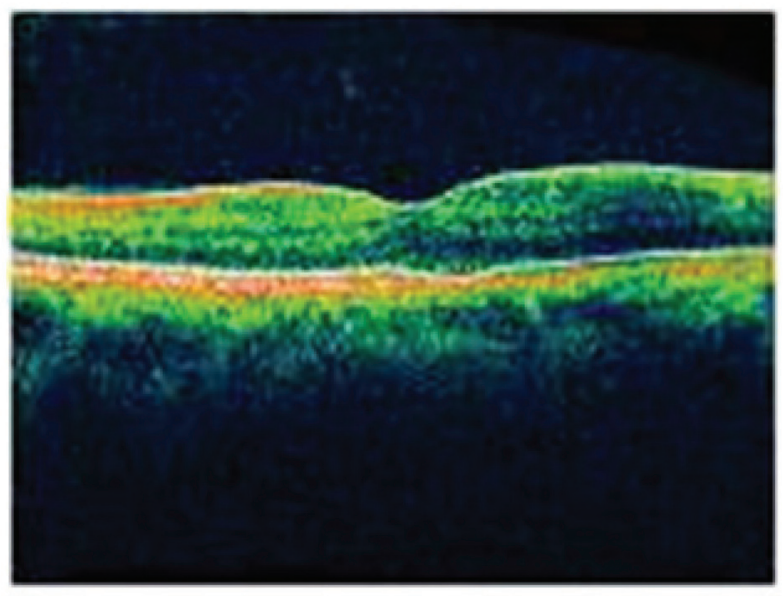

B. After 1 month of nepafenac treatment (262 microns)

Figure 3 Chronic/recalcitrant pseudophakic CME: Patient \#I2 OCT images. A) The patient shows retinal edema, with a retinal thickness of $690 \mu \mathrm{m}$ prior to nepafenac treatment. B) The patient shows resolution of retinal edema, with a retinal thickness of $262 \mu \mathrm{m}$ after one month of treatment with nepafenac.

Abbreviations: CME, cystoid macular edema; OCT, optical coherence tomography.

\section{References}

1. Solomon LD. Efficacy of topical flurbiprofen and indomethacin in preventing pseudophakic cystoid macular edema. Flurbiprofen-CME Study Group I. J Cataract Refract Surg. 1995;21:73-81.

2. Ursell PG, Spalton DJ, Whitcup SM, Nussenblatt RB. Cystoid macular edema after phacoemulsification: relationship to blood-aqueous barrier damage and visual acuity. J Cataract Refract Surg. 1999;25:1492-1497.

3. Ray S, D'Amico DJ. Pseudophakic cystoid macular edema. Semin Ophthalmol. 2002;17:167-180.

4. Wolf EJ, Braunstein A, Shih C, Braunstein RE. Incidence of visually significant pseudophakic macular edema after uneventful phacoemulsification in patients treated with nepafenac. $J$ Cataract Refract Surg. 2007;33:1546-1549.

5. Prieto JF, Dios E, Gutierrez JM, et al. Pars planitis: epidemiology, treatment, and association with multiple sclerosis. Ocul Immunol Inflamm. 2001;9:93-102.

6. Gulkilik G, Kocabora S, Taskapili M, Engin G. Cystoid macular edema after phacoemulsification: risk factors and effect on visual acuity. Can J Ophthalmol. 2006;41:699-703.

7. Miyake K, Ibaraki N. Prostaglandins and cystoid macular edema. Surv Ophthalmol. 2002;47(Supp1 1):S203-S218.

8. Flach AJ. The incidence, pathogenesis and treatment of cystoid macular edema following cataract surgery. Trans Am Ophthalmol Soc. 1998;96:557-634.

9. Bazan NG, de Abreu MT, Bazan HE, Belfort R Jr. Arachidonic acid cascade and platelet-activating factor in the network of eye inflammatory mediators: therapeutic implications in uveitis. Int Ophthalmol. 1990;14:335-344.

10. Heier JS, Topping TM, Baumann W, et al. Ketorolac versus prednisolone versus combination therapy in the treatment of acute pseudophakic cystoid macular edema. Ophthalmology. 2000;107:2034-2038; discussion, 2039.

11. Gillies MC, Sutter FK, Simpson JM, et al. Intravitreal triamcinolone for refractory diabetic macular edema: two-year results of a doublemasked, placebo-controlled, randomized clinical trial. Ophthalmology. 2006;113:1533-1538.

12. Choi JY, Buzney SM, Weiter JJ. Cystoid macular edema: current modes of therapy. Int Ophthalmol Clin. 2005;45:143-151.

13. Sivaprasad S, McCluskey P, Lightman S. Intravitreal steroids in the management of macular oedema. Acta Ophthalmol Scand. 2006;84:722-733.
14. Bucher RS, Hall E, Reed DM, et al. Effect of intravitreal triamcinolone acetonide on susceptibility to experimental bacterial endophthalmitis and subsequent response to treatment. Arch Ophthalmol. 2005;123:649-653.

15. Flach AJ, Stegman RC, Graham J, Kruger LP. Prophylaxis of aphakic cystoid macular edema without corticosteroids. A pairedcomparison, placebo-controlled double-masked study. Ophthalmology. 1990;97:1253-1258

16. Italian Diclofenac Study Group. Efficacy of diclofenac eyedrops in preventing postoperative inflammation and long-term cystoid macular edema. J Cataract Refract Surg. 1997;23:1183-1189.

17. Flach AJ, Dolan BJ, Irvine AR. Effectiveness of ketorolac tromethamine $0.5 \%$ ophthalmic solution for chronic aphakic and pseudophakic cystoid macular edema. Am J Ophthalmol. 1987;103:479-486.

18. Flach AJ, Jampol LM, Weinberg D, et al. Improvement in visual acuity in chronic aphakic and pseudophakic cystoid macular edema after treatment with topical $0.5 \%$ ketorolac tromethamine. Am JOphthalmol. 1991;112:514-519.

19. Rho DS. Treatment of acute pseudophakic cystoid macular edema: diclofenac versus ketorolac. J Cataract Refract Surg. 2003;29:2378-2384.

20. McColgin AZ, Raizman MB. Efficacy of topical Voltaren in reducing the incidence of postoperative cystoid macular edema. Invest Ophthalmol Vis Sci. 1999;40(Suppl):S289.

21. O'Brien TP. Emerging guidelines for use of NSAID therapy to optimize cataract surgery patient care. Curr Med Res Opin. 2005;21:1131-1137. Erratum in: Curr Med Res Opin. 2005;21:1431-2.

22. Gamache DA, Graff G, Brady MT, et al. Nepafenac, a unique nonsteroidal prodrug with potential utility in the treatment of trauma-induced ocular inflammation: I. Assessment of anti-inflammatory efficacy. Inflammation. 2000;24:357-370.

23. Hariprasad SM, Callanan D, Gainey S, et al. Cystoid and diabetic macular edema treated with nepafenac $0.1 \%$. J Ocul Pharmacol Ther. 2007;23:585-590

24. Hariprasad SM, Callanan D. Topical nepafenac $0.1 \%$ for treatment of chronic uveitic cystoid macular edema. Retin Cases Brief Rep. 2008;2:304-308.

25. Warren KA, Fox JE. Topical nepafenac as an alternate treatment for cystoid macular edema in steroid responsive patients. Retina. 2008; 28:1427-1434. 
26. Callanan D, Williams P. Topical nepafenac in the treatment of diabetic macular edema. Clin Opthalmol. 2008;2:999-1002.

27. Ke TL, Graff G, Spellman JM, Yanni JM. Nepafenac, a unique nonsteroidal prodrug with potential utility in the treatment of trauma-induced ocular inflammation: II. In vitro bioactivation and permeation of external ocular barriers. Inflammation. 2000;24:371-384.
28. Kapin MA, Yanni JM, Brady MT, et al. Inflammation-mediated retinal edema in the rabbit is inhibited by topical nepafenac. Inflammation. 2003;27:281-291. 